NPR. (2017, October 24). Majority of white Americans say they believe whites face discrimination. National Public Radio, Inc. Retrieved from https://www.npr.org/2017/10/24/559604836/ majority-of-white-americans-think-theyre-discriminated-against

Rockquemore, K. A., Brunsma, D. L., \& Delgado, D. J. (2009). Racing to theory or retheorizing race? Understanding the struggle to build a multiracial identity theory. Journal of Social Issues, 65(1), 13-34.

Rosenthal, L. (2016). Incorporating intersectionality into psychology: An opportunity to promote social justice and equity. American Psychologist, 71(6), 474-485.

Sue, D. W., Capodilupo, C. M., Torino, G. C., Bucceri, J. M., Holder, A., Nadal, K. L., \& Esquilin, M. (2007). Racial microaggressions in everyday life: Implications for clinical practice. American Psychologist, 62(4), 271-286.

Torres, L., Driscoll, M. W., \& Burrow, A. L. (2010). Racial microaggressions and psychological functioning among highly achieving African-Americans: A mixed-methods approach. Journal of Social and Clinical Psychology, 29(10), 1074-1099.

Williams, J. C., Phillips, K. W., \& Hall, E. V. (2014). Double jeopardy? Gender bias against women of color in science. San Francisco, CA: University of California Hastings College of Law. Retrieved from http://www.uchastings.edu/news/articles/2015/01/double-jeopardy-report.pdf

\title{
Intersectionally Insufficient: A Necessary Expansion of the Social-Structural Lens
}

\author{
Stephanie E. V. Brown and Sin-Ning Cindy Liu \\ Texas A\&M University
}

Miner et al.'s (2018) interpretation of gender inequity in STEM fields as a social-structural problem shifts the onus from "her" as the root of the problem to "us" as a society. However, despite noting the "even bleaker" outlook for women of color ${ }^{1}$ early on, the focal article lacks an intersectional focus, ignoring the differential experiences that exist between white women and women of color. Crenshaw's (1991) original work on intersectionality highlighted the fact that the experiences of women of color (WOC) often differ drastically from those of their White counterparts, and the subsequent body of intersectionality literature in a variety of fields reminds us that failing to include an intersectional perspective is an oversight we can no longer afford to make. With this in mind, we highlight the ways in which those at the sity.

Stephanie E. V. Brown, Texas A\&M University; Sin-Ning Cindy Liu, Texas A\&M Univer-

Correspondence concerning this article should be addressed to Stephanie E. V. Brown, Texas A\&M University, 4235 TAMU, College Station, TX 77840. E-mail: stephanieevbrown@tamu.edu

1 The term "women of color" often refers to women who are Black, Latina/Hispanic, Native American/American Indian, Asian, or multiracial. Women of color is an admittedly broad term, and we recognize that experiences of discrimination can vary based on the different socio-political histories that exist between racial and ethnic groups in various countries (Andersen \& Collins, 2011; Johnson, 2011) 
intersection of both gender and racial minority status face a "double bind" (Malcom \& Malcom, 2011), such that they are additionally disadvantaged by society's perceptions and expectations of the behavior of WOC.

\section{Social Constructionism and Intersectional Identities}

The focal article notes that the prototypical scientist is often perceived as a male. More so, the prototypical scientist is often perceived as a White male. Thus, as WOC in STEM differ from the prototype in two distinct ways, they are likely to face challenges that are both greater than and different from the challenges faced by White women in STEM. Stereotypically constructed traits of women of color are often thought of as incongruent with that of scientists. Depending on the specific race or ethnic background of the woman in question, they can be perceived as emotional, bossy, angry, submissive, lazy, and/or hypersexual, whereas scientists are thought of as "decisive, methodical, objective, unemotional, and competitive" (Miner et al., 2018, p. 273). Even the so-called "model minority" stereotype of Asians does not always work in favor of Asian women, who are often stereotyped as competent yet lacking in warmth and social skills (Fiske, Xu, Cuddy, \& Glick, 1999). These stereotypes may act as a barrier within selection systems because these processes are often heavily influenced by perceived fit and likeability (Garcia, Posthuma, \& Colella, 2008; Heilman, 2001). As such, the STEM pipeline in both academia and industry can be even more leaky for women of color.

Miner et al. (2018) note that identical curriculum vitae with differently gendered names result in lower ratings and starting salary offers for women (Moss-Racusin et al., 2012; Steinpres, Anders, \& Ritzke, 1999). A footnote in the same paragraph notes that a similar phenomenon occurs when names are manipulated to reflect a certain ethnicity. Resumes belonging to those with prototypically "White-sounding" names are more often selected than those belonging to "Black-sounding" names (Bertrand \& Mullainathan, 2004). However, these realities require more than a passing comment or brief acknowledgment-prior research indicates that dual-minority status can have dire consequences for WOC seeking employment in STEM fields, especially if the intersection of race and gender is not accounted for when designing institutional solutions to such problems.

\section{Social Exchange, Social Dominance, and Intersectionality}

Although Miner et al. (2018, p. 274) argue that men hold a larger share of "positive social value" than women per social dominance theory, it could also be posited that White women are still prescribed more "positive social value" than WOC. When race is examined, a more nuanced view of groupbased hierarchies emerges. Women of color (holding dual minority status as both women and ethnic minorities) may be seen as lower value exchange 
partners based on their group membership. This, in turn, leads to a lack of resource reciprocation-those with higher "positive social value" (i.e., men and White women) are less likely to share social resources such as information or access, leaving WOC to receive fewer socially exchanged resources than men or White women.

DiTomaso (2015) argued that in-group advantages provided by White individuals to other White individuals increases racial inequality in the workplace. White individuals who hold social resources (like information on tenure track positions, influence with hiring or promotion boards, or leads on applied careers) are likely to share those advantages with members of their racial group. This information exchange happens even earlier in the STEM pipeline, such as sharing information on undergraduate research assistantships or recommending students for graduate school positions. The lack of resources puts WOC at a disadvantage compared to their White counterparts, who often have stronger social networks with more resources available to share (DiTomaso, 2015). Thus, although all women report greater academic and family stress and lower levels of support than men do, we argue that the challenges faced by WOC in STEM are more arduous than those faced by White women in STEM because the exchange of information necessary to get and retain a STEM-related job is often not as readily provided.

\section{Practical Implications: Interventions for Women of Color}

WOC in STEM face unique barriers above and beyond those faced by White women. Therefore, it is necessary for industrial and organizational (I-O) psychologists to prepare interventions that are specifically tailored to meet the challenges experienced by WOC.

\section{Bias Training}

In regard to selection, I-O psychologists can partner with human resource teams and hiring or search committees to discuss schemas that may hamper diverse hiring practices. By creating and implementing implicit bias trainings, I-O psychologists can help selection committee members understand that their schemas of what constitutes a STEM professional may be biasing them against hiring WOC.

I-O psychologists can also design training programs that identify and target disrespect against WOC. WOC are more likely to bear the brunt of workplace discrimination (e.g., incivility, microaggressions, ostracism; Carter-Sowell \& Zimmerman, 2015), and those in academic STEM settings are also more likely to report that their students and colleagues do not treat them as expert scholars (Pittman, 2010). Implementing such programs can help WOC get the respect they have earned. 


\section{Selection Systems}

As I-O psychologists often design the selection systems used by organizations, we can promote systems that reduce subgroup differences and adverse impact, including using predictor methods other than cognitive ability testing (e.g., structured interviews and assessment centers) or combining cognitive ability tests with other predictors to assess a wider range of knowledge, skills, and abilities (KSAs; Ployhart \& Holtz, 2008). I-O psychologists should always strive to design and implement the best job-related selection systems. Although this process is not specific to women of color, ensuring structure in the decision-making process will also help ensure applicants have a fair chance regardless of the social resources and connections available to them.

\section{Retention}

To address retention challenges, social groups for WOC should be established to provide social and emotional support and combat feelings of tokenism, alienation, and isolation. Examples of social support structures include conferences or symposia for WOC, peer mentoring circles, and open forums. These gatherings can serve to assuage the feelings of tokenism, alienation, and isolation that WOC often feel (Turner, 2002; Xu \& Martin, 2011).

Human resource professionals within organizations can promote and encourage membership in professional scientific groups such as Black Women in Science and Engineering (BWISE), the National Association of Multicultural Engineering, or the Society for the Advancement of Chicanos and Native Americans in Science (SACNAS). Boeing is one such organization that encourages members to join an employee-run group as part of its diversity initiatives (Boeing, n.d.). These groups hold monthly meetings, provide opportunities for personal and professional development, and promote inclusive workplace practices. Membership in such groups can increase a woman's sense of belonging in her racial, gender, and career community, and provide members with a place to build a strong network of like-minded individuals.

\section{Socialization}

Finally, Miner et al. (2018) noted that the need for change starts far beyond the point where a woman enters the STEM workforce. Increased socialization must start early, and I-O psychologists can encourage organizations to invest in programs promoting diversity in STEM fields. This includes the implementing programs to give young women of color STEM-related experiences to provide the experience and social capital necessary to continue in the field. Of course, this requires that organizations expand their reach into underresourced areas. 
Organizations like Verizon, CISCO, and General Motors have invested in such programs, partnering with community organizations like Girl Scouts and Black Girls Code to invest in young women.

\section{Conclusion}

Johnson (2011) notes that treating women in STEM as a homogenous group serves only to obscure the unique experiences of women of color, even as we note that a variety of different groups comprise "women of color" as a whole. However, as race is often not a hidden identity and has large implications for women pursuing careers in STEM from early educational settings to higher education and beyond, we call for researchers on women in STEM to very intentionally address the intersection of gender and race while researching and proposing STEM initiatives in an effort to help advance all women. Full gender equity in STEM cannot be achieved if women of color are left behind.

\section{References}

Andersen, M. L., \& Collins, P. H. (2001). Race, class, and gender: An anthology (4th ed.). Belmont, CA: Wadsworth.

Bertrand, M., \& Mullainathan, S. (2004). Are Emily and Brendan more employable than Latoya and Tyrone? Evidence on racial discrimination in the labor market from a large randomized experiment. American Economic Review, 94, 991-1013.

Boeing. (n.d.). Diversity and inclusion at Boeing. Retrieved from http://www.boeing.com/principles/ diversity.page\#/groups

Carter-Sowell, A. R., \& Zimmerman, C. A. (2015). Hidden in plain sight: Locating, validating and advocating the stigma experiences of women of color. Sex Roles, 73, 399-407.

Crenshaw, K. (1991). Mapping the margins: Intersectionality, identity politics, and violence against women of color. Stanford Law Review, 43, 1241-1299.

DiTomaso, N. (2015). Racism and discrimination versus advantage and favoritism: Bias for versus bias against. Research in Organizational Behavior, 35, 57-77.

Fiske, S. T., Xu, J., Cuddy, A. C., \& Glick, P. (1999). (Dis)respecting versus (dis)liking: Status and interdependence predict ambivalent stereotypes of competence and warmth. Journal of Social Issues, 55, 473-489.

Garcia, M. F., Posthuma, R. A., \& Colella, A. (2008). Fit perceptions in the employment interview: The role of similarity, liking, and expectations. Journal of Occupational and Organizational Psychology, 81, 173-189.

Heilman, M. E. (2001). Description and prescription: How gender stereotypes prevent women's ascent up the organizational ladder. Journal of Social Issues, 57, 657-674.

Johnson, D. R. (2011). Women of color in science, technology, engineering, and mathematics (STEM). New Directions for Institutional Research, 152, 75-85.

Malcom, L. E., \& Malcom, S. M. (2011). The double bind: The next generation. Harvard Educational Review, 81, 162-171.

Miner, K. N., Walker, J. M., Bergman, M. E., Jean, V. A., Carter-Sowell, A., January, S. C., \& Kaunas, C. (2018). From "her" problem to "our" problem: Using an individual lens versus a social-structural lens to understand gender inequity in STEM. Industrial and Organizational Psychology: Perspectives on Science and Practice, 11(2), 267-290.

Moss-Racusin, C. A., Dovidio, J. F., Brescoll, V. L., Graham, M. J., \& Handelsman, J. (2012). Science faculty's subtle gender biases favor male students. Proceedings of the National Academy of Sciences, 109, 16474-16479. 
Pittman, C. T. (2010). Race and gender oppression in the classroom: The experiences of women faculty of color with White male students. Teaching Sociology, 38, 183-196.

Ployhart, R. E., \& Holtz, B. C. (2008). The diversity-validity dilemma: Strategies for reducing racioethnic and sex subgroup differences and adverse impact in selection. Personnel Psychology, 61, 153172.

Steinpreis, R. E., Anders, K. A., \& Ritzke, D. (1999). The impact of gender on the review of the curricula vitae of job applicants and tenure candidates: A national empirical study. Sex Roles, 41, 509-528.

Turner, C. S. V. (2002). Women of color in academe: Living with multiple marginality. The Journal of Higher Education, 73, 74-93.

Xu, Y. J., \& Martin, C. L. (2011). Gender differences in STEM disciplines: From the aspects of informal professional networking and faculty career development. Gender Issues, 28, 134-154.

\title{
A Cultural Perspective on Gender Inequity in STEM: The Japanese Context
}

\author{
Katsuhiko Yoshikawa \\ Shanghai Jiao Tong University \\ Akiko Kokubo \\ University of Shizuoka \\ Chia-Huei Wu \\ London School of Economics and Political Science
}

To understand gender inequality in STEM, Miner et al. (2018) illustrate how an individual lens and a social-structural lens provide complementary perspectives. They indicate that gender inequality in STEM should not be simply understood from an individual lens concerning individual choices and responsibilities but also a social-structural lens concerning societal structures, processes, and meanings associated with gender. In this commentary, we would like to bring a cultural perspective to the consideration of the STEM field. Specifically, we focus on gender inequity in STEM in Japan and elaborate how Japanese culture, which emphasizes masculinity, collectivism, and a tight culture, imposes a stronger social-structural influence on gender inequality in STEM and at the same time strengthens the use of the individual lens to explain the phenomena, making the issue of gender inequality more prominent.

Katsuhiko Yoshikawa, Antai College of Economics and Management, Shanghai Jiao Tong University; Akiko Kokubo, Division of Management and Information of Innovation, University of Shizuoka; Chia-Huei Wu, Department of Management, London School of Economics and Political Science.

Correspondence concerning this article should be addressed to Chia-Huei Wu, Department of Management, London School of Economics and Political Science, London, UK. E-mail: chiahuei.wu@gmail.com, c.wu14@lse.ac.uk 